\title{
Skin Stem Cell Resource Potential for Peripheral Nerve Repair Due to trauma of post regional anasthesia
}

\section{Sumartono, Christrijogo ${ }^{1}$, Fedik A Rantam², Eddy Rahardjo ${ }^{1}$, and Martia R Tacharina ${ }^{3}$}

${ }^{1}$ Department of Anesthesiology and Reanimasi Faculty of Medicine Universitas Airlangga, Surabaya, Indonesia

${ }^{2}$ Department of Stem Cell Institute Tropical Diseases Universitas Airlangga, Surabaya, Indonesia

${ }^{3}$ Faculty of Veterinary Medicine, Universitas Airlangga

\section{Abstract}

This study is undertaken to investigate the utilization of rabbit skin to be used as a source of stem cell, especially stem cells that is derived from the skin, to provide the healing and connection of damaged peripheral nerves. Based on the existing

Corresponding Author: Sumartono

Received: 03 October 2017 Accepted: 10 October 2017 Published: 29 November 2017

Publishing services provided by Knowledge E

(c) Sumartono et al. This article is distributed under the terms of the Creative Commons

Attribution License, which permits unrestricted use and redistribution provided that the original author and source are credited.

Selection and Peer-review under the responsibility of the VMIC Conference Committee. studies, there are many failures in the healing and connection of nerve due to trauma after regional anesthesia, and there is an opportunity that stem cells from the skin is potential to help the process of healing and even improvement in the failure of nerve grafting. 24 rabbits is used as experimental animals in this research. The 24 rabbit devided into 2 groups, the first group is a control group without suplementary therapy of rabbit skin stem cells, and the second group is the treated group that given rabbit skin stem cell as a supplementary therapy to treat the peripheral nerve damage post ansthesia. The result of this study shows that there is a significant differences between control and treated group. Statistical analysis was performed by using reliability test - intraclass correlation coefficient to assess interobserver variation and investigate the correlation.

Keywords: Stem Cell, Skin, Peripheral Nerve, Nerve Repair.

\section{Introduction}

Peripheral nerve lesions have been known as potential complications of regional anesthesia. Peripheral nerve lesions are characterized by pain, paresesthesia, sensory and motory deficits, or other neurological abnormalities. Frequent peripheral nerve lesion cases are cases of persistent neurological symptoms after barachial nerve blockade [1].

Anesthesiologist once claimed that there is a nerve damage to anesthesia malpracS OPEN ACCESS tice cases.Americam Society of Anathesiologist said that in 4138 cases of claims, 670 
$(16 \%)$ of them are nerve lesions associated with anesthesia. Overall regionally anesthesia more often associated with claims of nerve damage than general anesthesia $[2,3]$.

Several different sources of precursor cells have investigated of their potential applications for cases of peripheral nerve damage. The most promising candidates are transplant cells obtained from the skin, bone marrow, or fat (adipose, vcb). All of the tissues have demonstrated the ability to differentiate into cells that resembled schwann cells. Recent studies have shown that stem cells can be potential and promising suplementary therapy to nerve cells repair, so optimizing these therapies seriously is necessary, so that its potential can be clinically recognized [4].

The cursor cell derived from neural stem cells is a therapy that has a future prospect for a traumatized or degenerated nervous system. Human origin sources are embryonic stem cells and fetally derived neural tissues, but it is associated with ethical and clinical issues. The discovery of potential precursor cells of nerves in adult peripheral tissues such as skin, intestine, and pancreas is a potential source of adult stem cells for nerve transplantation [5].

The morphology of new neurons acquired from neural progenitor cells can be expressed from p75NTR which previously came from the proliferation and differentiation of a small biopsy of a scalp containing stem cells derived from the skin. Therefore there is a chance that stem cells from the skin can help the process of healing and even the failure of neural connections [6].

The aims of this study is to utilize skin as a source of stem cell, especially stem cells derived from the skin, to provide the healing and connection of damaged peripheral nerves.

Based on existing studies, many failures in the healing and connection of nerve due to trauma after regional anesthesia, and there is an opportunity that stem cells from the skin is potential to help the process of healing and even improvement in the failure of nerve grafting.

\section{Material and Methode}

This study used stem cells derived from experimental animal skin rabbits and human skin that is done culturally. This study was designed using experimental research in accordance with the problem that will be studied. 18 Rabbits has been used as sample of this. While the sampling technique was done by random allocation from the inclusion group. 
Statistical analysis was performed by using reliability test - intraclass correlation coefficient to assess interobserver variation and investigate the correlation.

\section{Result}

\subsection{Exploration And Isolation Of Mesenchymal Stem Cells From Rabbit's Skin}

The exploration of stem cells from rabbit skin begins with a dorsal back skin collection of 12 rabbits that has been randomized to a total of 24 rabbits. Skin collecting is done by cutting $2 \mathrm{~cm} \times 4 \mathrm{~cm}$ which is first done by anesthesia with ketamine and silazine, so the rabbit can recover normally.

\subsection{Stem Cell Cultures From Rabbit And Human Skin}

Rabbit skin stem cell cultures that growth monolayer. (A) stem cells in the first pasase with $70 \%$ confluence growth, (B) Stem cells in the second pasase with $90 \%$ confluence growth (inverted microscope Olympus with $40 x$ magnification)

In the first pasase, rabbit skin stem cell culture will grow monolayer on the 7 th day with 70\% confluence growth, at the second pasase stem cells grow with 90\% confluence on the $5^{\text {th }}$ day, whereas in the first pasase culture of rabbit skin stem cells growth monolayer at day 2 with a growth of $40 \%$ confluence, on the second pasase rabbit skin stem cells growth with 90\% confluence at day 6 .

The results of stem cell culture that used in this study is the second pasase, therefore stem cell characterization was performed on the first pasase, so that stem cells that been used for the study were homogeneous in the second pasase and still had high plasticity.

\subsection{Stem Cell Characterizatin}

\subsubsection{Flowcytometry}

Figure 5 shows that the characterization of mesenchymal stem cells is calculated based on the phenotype with protein markers ( $\mathrm{CD}_{105}, \mathrm{CD}_{90}, \mathrm{CD}_{73}$, and $\mathrm{CD}_{44}$ ) using a flowcitometry technique (FACS Calibury). Figure $A$ is an initial scatter process for determining the isomers according to the density of the stem cells. While the figure $B$ that indicated by the arrow is a marker $(+)$ on $\mathrm{CD}_{73}$ and $\mathrm{CD}_{105}$ 

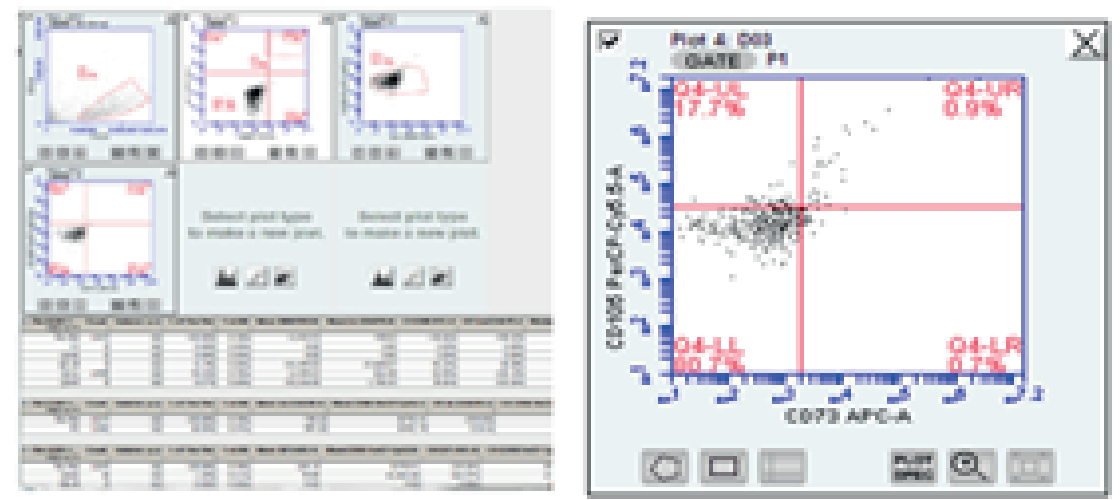

Figure 1: The Charaterisation of Mesenchymal Stemcells.
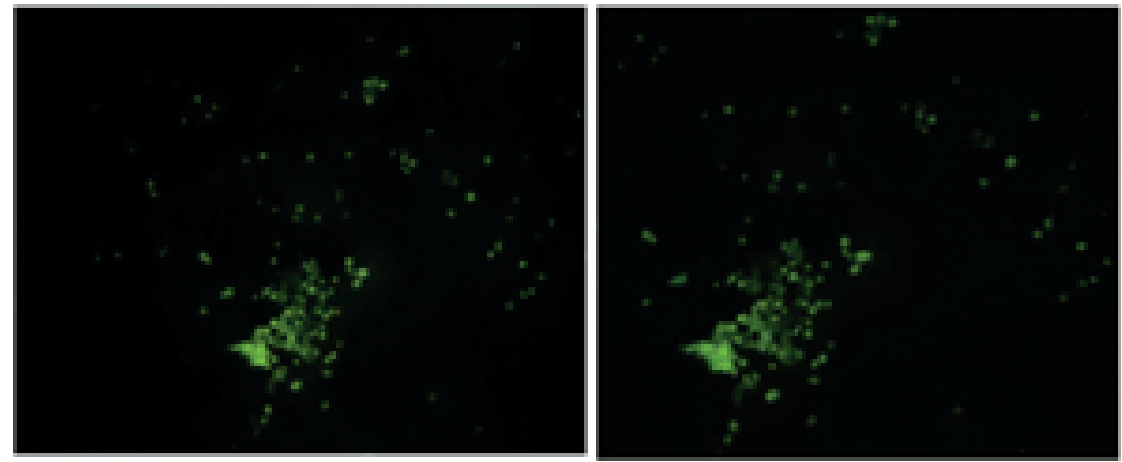

Figure 2: Mesenchymal stem cells from skin of 4 weeks rabbit imunocytochemistry staining of monoclonal antibody protein membran specific Nestin, fluoroscence. Visualisation with inverted microscope 100 times.

\subsubsection{Immunocytochemistry}

Immunocytochemistry is a method used to detect the expression of a specific protein or antigen in cells by using specific antibodies that will bind to proteins and antigens.

The result of stem cell culture not only to characterize the specific mesenchymal stem cell, but also to characterize for the possibility of stem cell proliferation toward progenitor (cell schwann), the examination done by immunocytochemical examination with antibodies that lead to progenitor cell that is nestin, And GFAP.

\subsubsection{Progenitor}

The development of monomucleated stem cells can be developed towards the progenitor of stem cells, which in its growth is directed toward the neurons by adding growth hormone to achieved progenitor stem cell growth ie serum forkolin and neuregulin $1 \beta$ $1 \%$. 


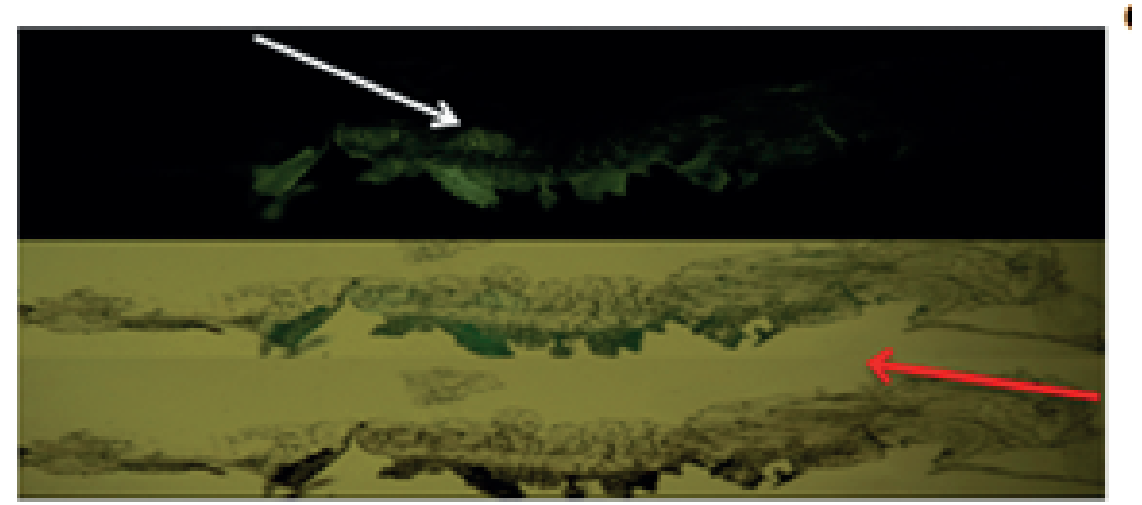

Figure 3: Labeling with PKH26 and counter staining of sciatic nerve stability + MSC allograft stem cells, migration appears from the left side to the right (red arrow direction) while the white arrow is the edge of the ischiadicus nerve joint margin.

\subsection{Labeling with $\mathrm{PKH} 26$ to investigate the migration}

The application of stem cell transplantation is performed by first anesthesia using ketamine and silazyne, so that the rabbit can recover normally.

All the rabbits treated until totally healed which then performed immunocytochemical observations as well as motor function where ischiadicus edge nerve is very dominant in the movement of hind legs of rabbit as the experimental animal. Another proof of the healing process is the improvement of nerve function with the examination of motor function with nerve stimulator tool and NCV (Nerve Conduction Velocity).

There is a differences between the treated group and control group which is the identification of the application results in rabbit as experimental animals who did not receive additional stem cells in peripheral nerve grafting (control group) was by looking at the results of ischiadicus nerve suture.

\subsubsection{Observation of PKH26 Labeling Results on Peripheral Nerves}

The results of the $\mathrm{PKH}_{2} 6$ labeling on stem cells from the skin, the healing process was observed finally with a fluorescence microscope to see the process of stem cell migration.

Figure 4 shows that there is a migration from the left side to the right side. In the Figure $A$, the results shows that there is an absorption of $\mathrm{PKH}_{2} 6$ color label that spreat out the color of goldish, and Fig. $B$ is an allograft nerve fragment with rhodamine color (a mixture of $\mathrm{PKH} 26$ ), while $\mathrm{C}$ is another illustration with a greenhouse microscope filter. 


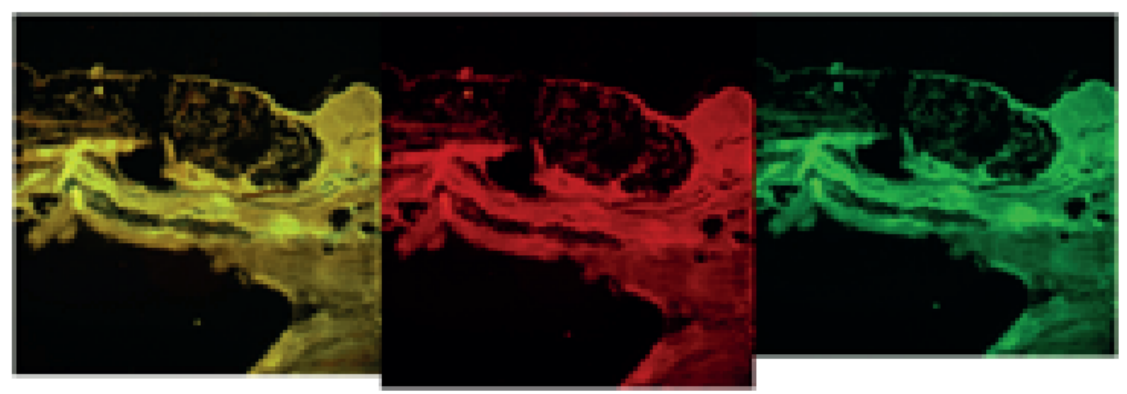

Figure 4: Labelling with PKH26 and counter staining and sciatic nerve conectivity + MSC allograft stem cells.

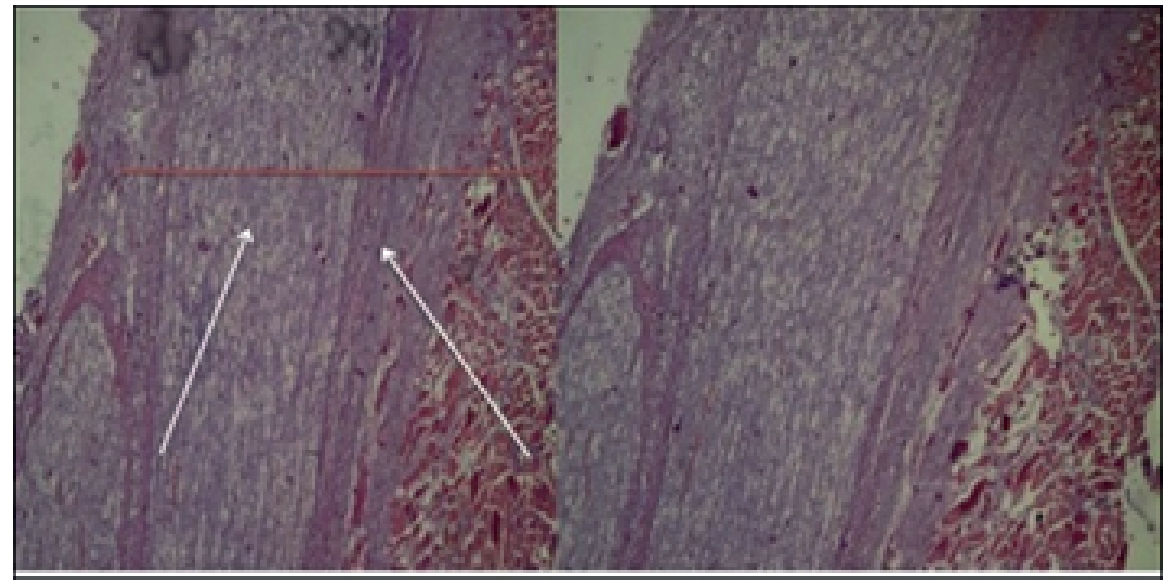

Figure 5: Perfect nerve conectivity.

\subsubsection{Immunohistochemical Examination of Transplanted Nerv Cells}

The Immunohistochemical examination is done of the peripheral nerves after healing. Examination is done in both study groups, both transplants using standard stem cells and without stem cells.

In the results of imuhistochemical examination, this study looked at the migration from the results of proliferation of stem cells towards the progenitor. Therefore the specific protein antibodies in the peripheral nerve, especially cell schwann, can be observed.

FIG. 9 shows that the loss of boundary observed in the rabbit group performed by stem cell transplants in both autologous and allograft groups. Fig.A shows a black arrow that indicates a peripheral nerve grafting area (inverted microscope Olympus with $40 \mathrm{x}$ magnification). Whereas image B used 400x magnification visible cells with a rather brownish absorption as the stem cell that has integrated with its environment and is detected with GFAP (+) antibodies. 
Figure 10 shows that neural connections are not well connected and its found that some undetectable nucleus of nerve cells with GFAP antibodies resulting in a less perfect observation.

\subsection{The axon diameter of integration process after healed}

In this study the axon diameter is meausred to look at the potential of healing as well as to identificate the microscopic shape of schwann cell that exist around the surgical wound after the healing of the process of perishing peripheral nerve injury.

The measurement of the total diameter of the axon is related to nerve regeneration because it indicates that there is a close relationship between the conduction velocity and the sheath thickness, between the conduction velocity and the axon or the total diameter [6]. In the previous studies, functional neural improvement after transplantation was performed by evaluating the histologic score of axon diameter $[7,8]$.

The axon diameter measurements were performed in accordance at 3 sites of the peripheral nerve region, ie $5 \mathrm{~mm}$ proximal and $5 \mathrm{~mm}$ distal lesions. The axon diameter is converted to score according to the histological score that is divided into several scores according to the next axon morphology.

1. (5) similar with the proximal part of the nerve

2. (4) large axon diameter and great number of axon

3. (3) great number of axon

4. (2) moderate number of axon

5. (1) few number of axon

6. (o) Scar (no axon)

\section{Discussion}

\subsection{Stem Cell Exploration from Rabbit Skin}

The previous studies shows that multipotent stem cells can be isolated from human skin. Differences in the location of skin culture will result in different stem cell numbers [9-12].

Rabbit skin stem cells have fewer micro-environments than human skin. In another study initially regulation of stem cells originating from the skin is controlled by micro or 
"niches". On the other hand many factors that can regulate the development of stem cells primarily are extrinsic factors and intrinsic factors. Examples of extrinsic factors are exposure to ultraviolet light, toxins, while intrinsic factors such as DNA damage, ROS [13-15].

The biological characters of stem cells in terms of the nature of proliferation and differentiation is faster than other sources. This is influenced by the regulation of signal and gene molecules such as Wint and other signaling genes that affect the particular anatomical location that governs how stem cells participate in tissue regeneration, maintenance, and micro-environment improvement. Therefore, the micro environment (niche) must have dimensions both anatomically and its function [16].

\subsection{Rabbit Skin Stem Cell Differentiation}

Rabbit skin is isolated and cultured, then the mononucleic cells will undergo differentiation. This can be driven by adding substance like growth factor in the medium.

\subsection{1.}

In this research, the researchers conducted a development towards the mencenchymal stem cells. CD 105, CD 90, CD 73, and CD 45 is used as markers and all markers expressed on the surface of this stem cell membrane. However, the results are not so predominantly positive $(+)$ (such as the results of flowcytometry examination in chapter 5 ). This has many influences which may cause the result to be less dominant $(+)$, such as the number of passages or splitting cells, so that the mensenchymal stem cells have undergone many changes to the progenitor of stem cells, as illustrated in the results of characterization with BD cocktail flowcytometry, negative results (-) with more marker and dominant marker antibodies in culture results in both skin sources and neuronal neural cells. However, once there is a mesenchymal stem cell source successfully cultured in marker (+) with some mesenchymal specific antibodies CD 90, CD 103, CD 73 and marker (-) CD 45 corresponding [17].

In an attempt to initiate differentiation was done by adding substance growth factors in the medium, this is evident in the morphological picture in Figure 5.19, wherein the development medium is added $1 \%$ fockolin and neuregulin $11 \%$ so that stem cells can proliferate and differentiate into progenitor cells that will develop into peripheral nerve cells such as dendrites, neuron, and axon. 


\subsubsection{GFAP Profile and Nestin Expresion}

Glial fibrillary acidic protein (GFAP) and Nestin is one of several marker profiles of peripheral nerve cells (schwan cell, astrocyte, dendrite, axon). Therefore, in this study stem cells identified based on the GFAP and Nestin proteins obtained in Figure 5.17, the results of cultures derived from the skin was stained using monoclonal antibodies of Nestin-specific membrane proteins that reacted positively to the Nestin protein, where this corresponds to the results of flowcytometry. Previously where many results / dominant with CD 105, CD 73, CD 90 negative marker, it is possible in this case that stem cells have changed properties into progenitor stem cells that become unipotent to peripheral nerve cells.

\subsection{The Potency of Rabbit Skin-Derived Stem Cell}

Schwan cells (peripheral nerves) can be derived from stem cells originating from skinderived precursor cress(SKPCs). Stem cells will respond to proven extrinsic cues to increase Schwann cell differentiation and proliferation of NC (Neural Crest) stem cells to produce highly enriched cultures in cells with morphology and biochemical phenotypes of Schwan cells in vivo [18].

Stem cell cultures originating from the skin prior to this are known as multipotent skin precursor culture that can be grown from the dermis of mammalian skin. skinderived precursor cress (SKPCs) produced nervs and in vitro mesodermal derived in skin. In the previous study, SKPCs has ability to (i) migrate to skin during embryogenesis, (ii) Persist in a particular dermal niche, and (iii) play a key role in normal physiological or pathological skin [19].

\subsubsection{Cell Migration and PKH26}

The result of this research showed that the mesenchymal stem cells isolated from skin expresed $\mathrm{CD}_{73}(+), \mathrm{CD}_{90}(+), \mathrm{CD}_{105}(+)$, but $\mathrm{CD}_{44 / 45}(-)$, and defferentiation ability of mesenchymal stem cells in to peripheral nerv cells was labeled with $\mathrm{PKH} 26$.

The mesenchymal stem cells migrated from proximal into distal repaired peripheral nervs. This result showed that migratory of stem cells was strongly influenced by chemotractants dissected by magrophages, hence the cells attached then followed by homing, proliferation, and differentiation, so that the microenvironment in the lesion area would improve. 


\subsubsection{Healing Quality}

The result of this research showed that healing quality of skin derived stem cells was very satisfying. This result proved that in addition to predominant stem cell progenitor factors, stem cells from skin also contain mensenchymal stem cells that are multipotent so that the wound healing process was very good.

\subsubsection{Nerv Cells Function}

Previous stdies showed that peripheral nerve lesions may have regeneration or healing, that may return to normal, depend on the severity of the lesion and lossed compound and connected tissue surround them [20].

\subsubsection{Axon Diameter and Its Corelation of Peripheral Nervs in Transplantation Process}

Nervs regeneration is complexed and strategic problem. Cell therapies are currently being developed to increase regeneration with peripheral myelin cell transplantation that can form schwan cells to secrete neurotrophic factors and participate in remyelination of the axon regeneration [21, 22].

The result of this research showed that there is a functional repaired and stem cells transplantation process can be a potential additional therapy for peripheral nervs micro regeneration. The transplantional scor of this research is 4 (good). That means that large numbers of large diameter axon and its potential to initiate the regeneration of peripheral nerve cells, that can simulate extracellular milieu and growth of axon as well as in vitro cells, in vivo in the appropriate implantation of the regeneration process as a regenerative source and improve nerve tissue reconstruction.

\subsection{Healing/Repair Process Acceleration}

The result of this researched showed that there are significant difference between allogenic group and control group. Control group has slow respons of electric impuls jitter. So that, if the regeneration process of nerve cells left normal without manipulation or additional therapy, then the process of length and healing will be hampered and can be toward to mal union. 


\subsubsection{The Accelerative Differences of Allo, Auto and Xeno in Healing Process}

The difference of healing from two wounds area shows the existence of molecular differences in the wound micro-environment. It is possible that the microenvironment of the skin is worse, because of the shift in back skin, so that it affects the micro $\mathrm{pH}$ environment. If there is a change of $\mathrm{pH}$ from normal it maight affect cell migration, cell attachment, cell homing and micro molecule envoment a.l. Intergrin, selektin, chemokine receptors [23].

Based on these studies, the use of mesenchymal allogeno stem cells in accelerated peripheral nerve repair, there was no difference in healing quality. The mesenchymal stem cells have multipotent properties and do not express MHC-I, so they do not induce local inflammatory responses that can inhibit proliferation and differentiation and rejection. Thus the stem cells given at the point of the lesion can integrate with the host cell tissue [23].

\subsection{Manifestation of This Research}

This reseach showed that skin is a new potential source of stem cell. The aims of this study is to prove the potential of stem cells originating from the skin on the healing process and function on traumatized nerves based on their function. Fore development of stem cell application research on peripheral nerve lesions using various stem cell sources that have the potential to differentiate into peripheral nerve cells.

\section{References}

[1] P. Audebert, P. Hapiot, J. Electroanal. Chem. 361 (1993) 177.

[2] J. Newman, Electrochemical Systems, 2nd ed., Prentice-Hall, Englewood Cliffs, NJ, 1991.

[3] A.R. Hillman, in: R.G. Linford (Ed.), Electrochemical Science and Technology of Polymers, vol. 1, Elsevier, Amsterdam, 1987, Ch. 5.

[4] B. Miller, Proc. $6^{\text {th }}$ Australian Electrochem. Conf., Geelong, Vic., 19-24 Feb., 1984; J. Electroanal. Chem., 168 (1984) 91.

[5] Jones, personal communication, 1992.

[6] Walsh S, Midha R. Practical Considerations Concerning the Use of Stem Cells for Peripheral Nerve Repair. Neurosurg Focus 2. 2009. 
[7] Linsley MD, Ekinci FJ, Ortiz D, 2005. Monitoring Thiobarbituric Acid-Reactive Substances (TBARs) as an assay for oxidative damage in neuronal cultures and central nervous system. Journal of Neuroscience Methods 141 : 219-222.

[8] Rantam FA, Ferdiansyah, Purwati, 2014. Stem cell mesenchymal, hematopoetik dan model aplikasi. 2nd Ed. Surabaya: Airlangga University Press, P. 38.

[9] Rokhind, S. 2009. Phototherapy in peripheral nerve regeneration: From basic science to clinical study. Journal of Neurosurgery 28 : (3).

[10] Toma JG, McKenzie IA, Bagli D, Miller FD 2005. Isolation and Characterization of Multipotent Skin-Derived Precursors from Human Skin. Stem Cells 23: 727-737

[11] Mc Kenzie IA, Biernaskie J, Toma JG, Midha R, Miller FD,2006. Skin Derived Precursors Generate Myelinating Schwann Cells for the Injured and Dysmyelinated Nervous System. The Journal of Neuroscience $24: 6651-6660$.

[12] Hunt DPJ, Morris PN, Sterling J, 2008. A Highly Enriched Niche of Precursor Cellswith Neuronal and Glial Potential Within the Hair Follicle Dermal Papilla of AdultSkin

[13] Gago N. Pérez-L冈pez V. Sanz-Jaka JP. Cormenzana P. Eizaguirre I. Bernad A. Izeta A. Age-dependent depletion of human skin-derived progenitor cells. Stem Cells. 2009;27:1164-1172. [PubMed]

[14] Morris RJ. Liu Y. Marles L. Yang Z. Trempus C. Li S. Lin JS. Sawicki JA. Cotsarelis G. Capturing and profiling adult hair follicle stem cells. Nat Biotechnol. 2004;22:411417. [PubMed]

[15] Chen FG. Zhang WJ. Bi D. Liu W. Wei X. Chen FF. Zhu L. Cui L. Cao Y. Clonal analysis of nestin(-) vimentin(+) multipotent fibroblasts isolated from human dermis. J Cell Sci. 2007;120:2875-2883. [PubMed]

[16] Kim HS, Oh SK, Park YB, 2005. Methods for deprivation of human embrionic stem cells.Stem Cells; 23: 1228-33.

[17] Kamadjaja DB. Purwati. Rantam FA. Ferdiansyah. Coen P.The Osteogenic Capacity of Human Amniotic Membrane Mesenchymal Stem Cell (hAMSC) and Potential for Application in Maxillofacial Bone Reconstruction in Vitro Study. J. Biomedical Science and Engineering, 2014, 7, 497-503

[18] Linsley MD, Ekinci FJ, Ortiz D, 2005. Monitoring Thiobarbituric Acid-Reactive Substances (TBARs) as an assay for oxidative damage in neuronal cultures and central nervous system. Journal of Neuroscience Methods $141:$ 219-222.

[19] Mc Kenzie IA, Biernaskie J, Toma JG, Midha R, Miller FD,2006. Skin Derived Precursors Generate Myelinating Schwann Cells for the Injured and Dysmyelinated Nervous System. The Journal of Neuroscience $24: 6651-6660$ 
[20] Fernandes KJ. McKenzie IA. Mill P. Smith KM. Akhavan M. Barnabé-Heider F. Biernaskie J. Junek A. Kobayashi NR, et al. A dermal niche for multipotent adult skin-derived precursor cells. Nat Cell Biol. 2004;6:1082-1093.

[21] Burnett Mgand Zager El, 2004.Pathophysiology of peripheral nerve injury: a brief review, Neurosurg Focus 16 (5):Article 1

[22] Radtke C Schmitz B. Spies M, Kocsis JD, Vogt PM Peripheral glial cell differentiation from neurospheres derived from adipose mesenchymal stem cells. International Journal of Developmental Neuroscience. 27(8): 817-823

[23] Rochkind S. Nevo Z. 2014. Recovery of Peripheral Nerve with Massive Loss Defect by Tissue Engineered Guiding Regenerative Gel. Biomed Research International. 